\title{
Fluorescence Studies of $\mathrm{Nd}^{+3}$ Ions in Phosphate Glass
}

\author{
P. KOTHARI ${ }^{1 *}$ and R. K. NARIYAL ${ }^{2}$ \\ ${ }^{1}$ Department of Chemistry, Govt. P.G. College Berinag, Pithoragarh, Uttarakhand, India \\ ${ }^{2}$ Department of Chemistry, Govt. Polytechnic College Lohaghat, Uttarakhand, India \\ drpramodkothari@gmail.com
}

Received 19 March 2014 / Accepted 21 April 2014

\begin{abstract}
Tripositive neodymium ion doped phosphate glass has been prepared by melt-quenching technique. The final composition (by weight) was approximately $\mathrm{Na}\left(\mathrm{PO}_{3}\right)_{6} 70 \%-\mathrm{BaO} 15 \%-\mathrm{PbO} 10 \%$ $\mathrm{Al}_{2} \mathrm{O}_{3} 5 \%-\mathrm{R}$ Ln (Where $\mathrm{R}=0.5 \%$ and $\mathrm{Ln}=\mathrm{Nd}^{+3}$ ). The experimental oscillator strengths were calculated from the areas under the absorption bands. Judd-Offelt parameters $\left(\Omega_{\lambda}\right)$ evaluated using the observed spectral intensities have been used to compute various laser parameters viz., spontaneous emission probability (A), radiative life time $(\tau)$ and stimulated emission cross-section $\left(\sigma_{\mathrm{p}}\right)$. The bonding environment surrounding the rare earth (RE) ion has also been discussed.
\end{abstract}

Keywords: Phosphate glass, Fluorescence spectrum, Absorption spectrum, Radiative properties

\section{Introduction}

Phosphate Glasses are both scientifically and technologically important materials because they generally offer some unique physical properties better than other Glasses ${ }^{1}$. Phosphate glass exhibit very important physical properties such as low melting temperature, high thermal expansion coefficient, low glass transition temperature, low softening temperature and high UV transmission ${ }^{2,3}$. Despite their solubility, the low processing temperature has led these glasses to be used in applications such as glass to metal seals, low temperature enamels for metals and for optical elements ${ }^{4}$.

Also the optical properties like transparency at the excitation and the lasing wavelengths, the spectroscopic properties of the lasing ion, thermo-optic properties, nonlinear optical properties, the fundamental absorption edge and absorption by multiphonon processes depend upon the composition of inorganic glass forming systems and modifiers ${ }^{5,6}$. The choice of suitable glass formers and modifiers help in tailoring the laser glass to meet the specific requirements. One of the first solid-state lasers was demonstrated in 1961 in $\mathrm{Nd}^{+3}$ doped glasses. Lasing in an $\mathrm{Nd}^{+3}$ doped multi component glass fiber was reported three years later. The same material structure was exploited to demonstrate the first thin-film waveguide glass amplifier, in $1972^{7}$ and the first integrated optical glass laser, in $1974^{8}$. Since then, many remarkable results in the development of more efficient glass matrices and in the actual fabrication of rare-earth-doped glass integrated optical amplifiers have been achieved ${ }^{9-11}$. 
Recently, we have carried out fluorescence of $\mathrm{Nd}^{3+}$ doped phosphate glass with a view to develop suitable glass for laser action in the visible region. Judd-Offelt parameters $\left(\Omega_{\lambda}\right)$ evaluated using the observed spectral intensities have been used to compute various laser parameters viz., spontaneous emission probability $(\mathrm{A})$, radiative life time $(\tau)$ and stimulated emission cross-section $\left(\sigma_{\mathrm{p}}\right)$ for different fluorescence lines have been evaluated.

\section{Experimental}

Rare earth doped Phosphate glass was prepared by melt quenching technique. The composition (by weight) was approximately $\mathrm{Na}\left(\mathrm{PO}_{3}\right)_{6} 70 \%-\mathrm{BaO} 15 \%-\mathrm{PbO} \quad 10 \%-\mathrm{Al}_{2} \mathrm{O}_{3} \quad 5 \%$ - $\mathrm{R}$ Ln (Where $\mathrm{R}=0.5 \%$ and $\mathrm{Ln}=\mathrm{Nd}^{+3}$ ) from reagents of analytical grade in $10 \mathrm{~g}$ batches. The $\mathrm{Nd}_{2} \mathrm{O}_{3}$ ion added to the host glass matrix was $99.99 \%$ purity. The glass material was mixed in an agate pestle mortar for two hours and was thermally treated for 4 hours in a platinum crucible at $1200 \pm 25^{\circ} \mathrm{C}$. Homogeneity of the melt was ensured by stirring the melt with a platinum rod from time to time. The melt was quenched by pouring into rectangular shaped mould placed on a steel plate. The glass specimen was polished using cerium oxide powder and again annealed. The glass specimens contained no crystalline phase as revealed by x-ray diffractogram of the specimen.

The fluorescence spectrum was recorded using a Perkin Elmer Luminescence spectrophotometer model LS50B in the spectral range 200-900 nm. The absorption spectrum was recorded at room temperature in the visible region using a double beam spectrophotometer with a resolution of $0.5 \mathrm{~nm}$. The length and width of the rectangular glass specimen was measured with the help of Vernier calliper, while the path length was measured with a screw gauge. The refractive index of glass specimens were measured on an Abbé refractometer (ATAGO 3T). An ordinary lamp was used as the light source.

\section{Results and Discussion}

Eight bands have been observed in the absorption spectrum and they have been assigned by comparing their positions with the energy level scheme of $\mathrm{LaF}_{3}: \mathrm{Nd}^{3+}$, published by Carnall et. al. ${ }^{12}$ All transitions in the absorption spectrum of $\mathrm{Nd}^{3+}$ start from the ground state ${ }^{4} \mathrm{I}_{9 / 2}$ to the various excited states, their peak position and assignments have been given in Table 2.

Table 1. Fluorescence transition and radiative properties of phosphate glass with $0.5 \mathrm{wt} \%$ doping concentration of $\mathrm{Nd}^{3+}$ ion

\begin{tabular}{lclcc}
\hline Transitions & $\lambda_{\max }, \mathrm{nm}$ & $\mathrm{A}, \mathrm{sec}^{-1}$ & $\tau, \mu \mathrm{sec}$ & $\sigma_{\mathrm{p}}, 10^{-20}, \mathrm{~cm}^{2}$ \\
\hline${ }^{4} \mathrm{~F}_{3 / 2} \rightarrow{ }^{4} \mathrm{I}_{9 / 2}$ & 882 & 1391.926 & 718 & 1.408 \\
\hline
\end{tabular}

Table 2. Experimental oscillator strength $\left(\mathrm{P}_{\exp }\right)$ measured $\left(\mathrm{S}_{\text {exp }}\right)$ calculated $\left(\mathrm{S}_{\text {cal }}\right)$ absorption line strengths and Judd- ofelt intensity parameters for the $\mathrm{Nd}^{3+}$ doped Phosphate glass:

\begin{tabular}{lcclcc}
\hline Absorption bands & $\lambda, \mathrm{nm}$ & $\mathrm{P}_{\text {exp }, .10} 0^{-6}$ & $\mathrm{~S}_{\text {exp }}, 10^{-20}$ & $\mathrm{~S}_{\text {cal }}, 10^{-20}$ & $\Delta \mathrm{S}, 10^{-20}$ \\
\hline${ }^{4} \mathrm{I}_{9 / 2} \rightarrow{ }^{4} \mathrm{~F}_{5 / 2},{ }^{2} \mathrm{H}_{9 / 2}$ & 798 & 7.74 & 4.179 & 4.054 & 0.124 \\
${ }^{4} \mathrm{~F}_{7 / 2}{ }^{4} \mathrm{~S}_{3 / 2}$ & 748 & 6.85 & 3.394 & 3.561 & -0.167 \\
${ }^{4} \mathrm{~F}_{9 / 2},{ }^{4} \mathrm{G}_{5 / 2},{ }^{2} \mathrm{G}_{7 / 2}$ & 680 & 0.94 & 0.431 & 0.265 & 0.165 \\
${ }^{4} \mathrm{G}_{7 / 2}$ & 583 & 17.50 & 6.908 & 6.890 & 0.017 \\
${ }^{4} \mathrm{G}_{9 / 2}$ & 526 & 5.62 & 1.996 & 1.386 & 0.609 \\
${ }^{2} \mathrm{P}_{1 / 2},{ }^{2} \mathrm{D}_{5 / 2}$ & 511 & 2.56 & 0.886 & 0.580 & 0.305 \\
${ }^{4} \mathrm{D}_{3 / 2},{ }^{4} \mathrm{D}_{1 / 2}$ & 432 & 0.67 & 0.195 & 0.231 & -0.036 \\
\hline \multicolumn{5}{c}{$\Omega_{2}=3.1029, \Omega_{4}=5.9872, \Omega_{6}=4.9870$}
\end{tabular}


The intensities of the observed bands have been measured in terms of line strength $S_{\text {exp }}$, calculated from the observed oscillator strength of the absorption bands, have also been included in Table 2. These values serve as a basis for the calculation of the three phenomenological parameters, $\Omega_{\lambda},(\lambda=2,4,6)$, known as Judd-Offelt parameters ${ }^{13,14}$. The Judd-Offelt intensity parameters $\Omega_{2}, \Omega_{4}$ and $\Omega_{6}$ found by least squares fit method ${ }^{15,16}$ have been presented in Table 2 for the $\mathrm{Nd}^{3+}$ doped Phosphate glass. The calculated line strengths $\left(\mathrm{S}_{\mathrm{cal}}\right)$ have been compared with the experimental measured line strengths $\left(\mathrm{S}_{\mathrm{exp}}\right)$.

In the phosphate glass specimen it has been observed that $\Omega_{4}>\Omega_{6}>\Omega_{2}$. The most intense band in the Absorption spectra of $\mathrm{Nd}^{+3}$ doped phosphate glass specimens around 350 $\mathrm{nm}\left({ }^{4} \mathrm{I}_{9 / 2} \rightarrow{ }^{4} \mathrm{D}_{3 / 2},{ }^{4} \mathrm{D}_{1 / 2}\right)$ has been used for the excitation wavelength. As a consequence of which one fluorescence band around 882 is observed, it has been assigned to the transition ${ }^{4} \mathrm{~F}_{3 / 2} \rightarrow{ }^{4} \mathrm{I}_{9 / 2}$.

In the case of $\mathrm{Nd}^{+3}$ doped phosphate glass specimens the values of spontaneous emission probability (A) is high for ${ }^{4} \mathrm{~F}_{3 / 2} \rightarrow{ }^{4} \mathrm{I}_{9 / 2}$ transition. Stimulated emission cross section $\left(\sigma_{p}\right)$ is a most important laser parameter. Its value signifies the rate of energy extraction from the laser material. The value of stimulated emission cross section $\left(\sigma_{\mathrm{p}}\right)$ is also higher for the above transition suggesting that under suitable circumstances, it can be used as a good laser transition. The values of $\mathrm{A}, \tau, \sigma_{\mathrm{p}}$ have been shown in Table 1 for $\mathrm{Nd}^{+3}$ doped glass specimen. The value of fluorescence branching ratio $(\beta)$ is calculated in those cases where more than one transition is observed.

\section{References}

1. Tongwei L, Zhengxin T, Weiwei J and Xiaoyang G, Engineering Materials, 2008, 368-372, 1446-1448.

2. Franks K, Abrahams I, Georgiou G and Knowles J C, Biomaterials, 2001, 22(5), 497 501; DOI:10.1016/S0142-9612(00)00207-6

3. Talib Z A, Loh Y N, Sidek H A A, Yusoff W M D W, Yunus W M M and Shaari A H, Ceramic International, 2004, 30(7), 1715-1717; DOI:10.1016/j.ceramint.2003.12.146

4. $\quad$ Shih P Y, Yung S W and Chin T S, J Non Cryst Solids, 1998, 224(2), 143-152; DOI:10.1016/S0022-3093(97)00460-2

5. Weber M J, Ziegler D C and Angell C A, J Appl Phys., 1982, 53, 4344.

6. Weber M J, J Non Cryst Solids, 1982, 47(1), 117-133; DOI:10.1016/00223093(82)90350-7

7. $\quad$ Miranday J P, Jacoboni C and Depape R, J Non-Cryst Solids, 1981, 43(3), 393-401; DOI:10.1016/0022-3093(81)90107-1

8. Snitzer E, Phys Rev Lett., 1961, 7, 444.

9. Koester C J and Snitzer E, Appl Opt., 1964, 3(10), 1182-1186.

10. Yajima H, Kawase S. and Sekimoto Y, Appl Phys Lett., 1972, 21(9), 407-409; DOI:10.1063/1.1654432

11. Saruwatari M and Izawa T, Appl Phys Lett., 1974, 24(12), 603-605; DOI:10.1063/1.1655071

12. Carnall W T, Fields P R and Rajnak K, J Chem Phys., 1968, 49, 4424- 4442.

13. Judd B R, Phys Rev., 1962, 127, 750.

14. Ofelt G S, J Chem Phys., 1962, 37(3), 511; DOI:10.1063/1.1701366

15. Krupke W F, IEEE J Quantum Electron, 1971, QE-7, 153 and 1974 QE-10, 450.

16. Weber M J, J Non Cryst Solids, 1990, 123(1-3), 208-222;

DOI:10.1016/0022-3093(90)90786-L 